\title{
EVALUASI PENGGUNAAN OBAT ASMA PADA PASIEN GERIATRI DI INSTALASI RAWAT JALAN RSUD KRATON KABUPATEN PEKALONGAN
}

\section{EVALUATION OF THE USE ASTHMA DRUG IN GERIATRIC PATIENTS IN THE OUTPATIENT INSTALLATION OF THE KRATON REGENCY OF PEKALONGAN}

\author{
Khafizah Ulfa Ulya, Ainun Muthoharoh, Wahyu Ersila, Wulan Agustin \\ Ningrum \\ Universitas Muhammadiyah Pekajangan Pekalongan \\ Jl. Raya Ambokembang No.8 - Pekalongan \\ Email : hafizahulfa29@yahoo.com No Hp:08561004584
}

Submitted : 26 Februari 2021 Reviewed : 9 Maret 2021 Accepted : 24 Maret 2021

\begin{abstract}
ABSTRAK
Asma merupakan salah satu penyakit yang mungkin saja tidak bisa disembuhkan secara total dan tidak bisa disembuhkan dalam waktu dekat serta akan terbebas dari serangan asma berikutnya. Oleh karena itu perlu dilakukan evaluasi terapi terkait dengan ketepatan penggunaan obat, tepat obat, tepat dosis, tepat indikasi, tepat lama pemberian. Penelitian ini bertujuan untuk mengetahui evaluasi penggunaan obat pada pasien geriatri di instalasi rawat jalan RSUD Kraton Kabupaten Pekalongan periode Januari-Desember tahun 2019. Metode penelitian ini menggunakan metode exhaustive sampling, jumlah sampel sebanyak 35 sampel diambil berdasarkan kriteria inklusi yaitu data rekam mediknya lengkap, pasien yang di diagnosa penyakit asma dan berusia 60 tahun keatas. Data yang diperoleh kemudian dianalisis secara deskriptif. Hasil penelitian ini menunjukkan bahwa pasien geriatri yang mengalami kasus asma yang terbanyak adalah perempuan (54\%) dengan kelompok usia lanjut usia (60-74 tahun) sebanyak (82\%). Hasil evaluasi penggunaan obat asma yang terjadi pada pasien geriatri meliputi tepat dosis sebanyak $(85,7 \%)$, tepat indikasi sebanyak (100\%), tepat obat sebanyak (100\%), tepat cara pemberian (100\%). Berdasarkan data hasil penelitian dapat disimpulkan bahwa ketepatan dosis dan juga ketepatan obat belum tepat sehingga perlu adanya peningkatan ketepatan dosis dan obat asma pada pasien geriatri
\end{abstract}

Kata kunci: asma, rawat jalan, ketepatan obat

\section{ABSTRACT}

Asthma is a disease that may not be completely cured and cannot be cured in the near future which will be free from the next asthma attack. Therefore it is necessary to evaluate the therapy with the right use of the drug, the right drug, the right dose, the right indication, the right time to offer it. This study aims to see the evaluation of drug use in geriatric patients in the outpatient installation of Kraton Hospital, Pekalongan The research method used the exhaustive sampling method, the number of samples was 35 samples taken based on inclusion criteria, namely medical record data. complete, patients diagnosed with asthma and aged 60 years and over. The data were then obtained descriptively. The results of this study indicate that the patients who experience the most asthma cases are women (54\%) with elderly (60-74 years) as much as (82\%). The results of the evaluation of 
asthma drug use that occurred in geriatric patients included the right dose (85.7\%), the right indication (100\%), the right drug (100\%), the right way to present (100\%).

Keywords: asthma, outpatient, medication accuracy

\author{
Penulis Korespondensi : \\ Khafizah Ulfa Ulya \\ Universitas Muhammadiyah Pekajangan Pekalongan \\ Jl. Raya Ambokembang No. 08 Pekajangan-Pekalongan \\ Email : hafizahulfa29@yahoo.com No Hp:08561004584
}

\title{
PENDAHULUAN
}

Menurut World Health Organization (WHO) 2017 Asma merupakan suatu masalah kesehatan yang sering ditemukan dikalangan masyarakat dan memiliki angka kesakitan dan juga kematian yang tinggi. Menurut Badan Penelitian dan Pengembangan Kesehatan tahun 2018 berdasarkan laporan WHO Desember 2016, tercatat pada tahun 2015 terdapat 383.000 orang yang meninggal dunia karena mempunyai penyakit asma. Berdasarkan laporan Riset Kesehatan Dasar Nasional pada tahun 2018 jumlah pasien asma sebanyak 2,4\%. Menurut data dari DINKES Provinsi JAWA TENGAH prevalensi dari kasus asma di Jawa Tengah pada tahun 2012 yaitu sebesar 140.026, sedangkan pada tahun 2013 sebesar 113.028 dan kasus tertinggi di Kota Surakarta sebanyak 10.393. Menurut data dari RISKESDAS Jawa Tengah (2018) prevalensi dari kasus asma sebanyak 26,2\% dari kasus tersebut lebih banyak di derita pada geriatri dari usia 65-74 tahun sebanyak 4,5\% sedangkan di usia 75 tahun keatas sebanyak $5,1 \%$.

Salah satu efek samping dari pengobatan pada pasien geriatri atau lanjut usia diantaranya gangguan kardiovaskuler, maka lebih baik menghindari penggunaan agonis $\beta$ 2, karena penggunaan golongan tersebut dapat menyebabkan takikardia. Jika masih tetap diperlukan, maka lebih baik menggunakan kombinasi antara agonis $\beta-2$ dengan antikolinergik. Penggunaan pada teofilin juga tidak dapat disarankan, atau harus dengan pengawasan yang ketat, karena pada pasien geriatri klirens dari teofilin dapat menurun sehingga bisa memicu terjadinya kekambuhan pada gangguan jantung yang ada. Penggunaan pada steroid sistemik jangka panjang juga dapat berpotensi dapat menggangu metabolisme pada tulang sehingga dapat menyebabkan osteoporosis (Ikawati, 2011).

Ketidakpatuhan pasien dalam proses pengobatan secara umum dapat meningkatkan risiko berkembangnya masalah kesehatan atau memperpanjang atau memperburuk kesakitan yang sedang diderita. Faktor yang mempengaruhi kepatuhan pasien dalam berobat diantaranya adalah faktor obat dan faktor penderita. Faktor obat yang mempengaruhi kepatuhan adalah: pengobatan yang sulit dilakukan tidak menunjukkan kearah penyembuhan, waktu yang lama, adanya efek samping obat. Faktor penderita yang 
menyebabkan ketidakpatuhan adalah umur, jenis kelamin, pekerjaan, anggota keluarga, saudara. Selain itu ketidakpatuhan penggunaan obat pada penderita asma membuat penderita tidak mendapatkan pengobatan yang tepat sehingga kondisi dapat memburuk, derajat asma meningkat, menurunkan kualitas hidup serta meningkatkan risiko kematian (Sarafino., dkk, 2011).

Pengobatan secara efektif telah dilakukan untuk menurunkan morbiditas karena efektivitas terapi hanya tercapai jika ketepatan obat pada pasien telah sesuai. Penggunaan obat dikatakan rasional apabila pasien menerima pengobatan yang sesuai dengan kebutuhan selama waktu yang sesuai.

Penggunaan obat yang rasional harus memenuhi beberapa kriteria berikut tepat obat, tepat indikasi, tepat dosis, dan tepat cara pemberian (Okti, dkk., 2016). Hasil studi pendahuluan yang diteliti dari ketiga Rumah Sakit di Kabupaten Pekalongan Pada tanggal 20 Januari 2020 menyerahkan surat kepada petugas rekam medis di RSUD Kajen, RSUD Kraton dan RSI PKU Muhammadiyah Pekajangan.Hasil yang didapat dari ketiga Rumah sakit tersebut adalah: data dari hasil rawat jalan RSUD Kajen sebanyak 65 pasien, data dari RSUD Kraton sebanyak 53 pasien, dan data dari RSI PKU Muhammadiyah Pekajangan sebanyak 47 pasien.

\section{METODE PENELITIAN}

Penelitian ini termasuk dalam penelitian observasional non-eksperimental dianalisis secara deskriptif dengan pendekatan retrospektif. Data rekam medis yang digunakan yaitu pasien asma berusia 60 tahun keatas di Instalasi Rawat Jalan RSUD Kraton Kabupaten Pekalongan. Alat yang digunakan pada penelitian ini adalah lembar pengumpul data dan daftar jurnal referensi terkait penelitian ini. Kriteria inklusi pada penelitian ini yaitu Data rekam mediknya lengkap. Pasien yang didiagnosa penyakit asma dan berusia 60 tahun keastas. Sedangkan kriteria ekslusinya adalah Data rekam medik yang tidak bisa terbaca dengan jelas.

Penelitian ini dilakukan di RSUD Kraton Kabupaten Pekalongan dengan rekam medis periode Januari- Desember 2019. Analisis data menggunakan analisa univariate dengan SPSS versi 16 untuk mengetahui distribusi frekuensi dari hasil yang di dapat.

\section{HASIL DAN PEMBAHASAN}

Pada penelitian ini, jumlah pasien asma yang memenuhi kriteria inklusi sebanyak 35 pasien. Karakteristik pasien asma di Intalasi rawat inap RSUD Kraton Kabupaten Pekalongan periode Januari-Desember 2019 ini dilihat berdasarkan jenis kelamin dan usia. 


\section{A. KARAKTERISTIK}

\section{Jenis Kelamin}

\section{Tabel I. Berdasarkan Jenis Kelamin Pasien asma Karakteristik Jumlah Persentase}

(\%)

\begin{tabular}{lll}
\hline Laki-laki & 16 & 45 \\
Perempuan & 19 & 54 \\
\hline Total & 35 & 100 \\
\hline
\end{tabular}

Berdasarkan tabel I jumlah pasien yang berjenis kelamin perempuan sebanyak 19 (54\%) pasien dan laki-laki sebanyak 16 (45\%) pasien. Dilihat dari hasil data tersebut bahwa pasien asma pada pasien geriatri lebih banyak pasien perempuan jika dibandingkan dengan pasien laki-laki yang datanya lebih sedikit dari perempuan. Hasil penelitian ini sesuai dengan Hasil penelitian ini sesuai dengan data dari sumber statistik asma pada WHO bahwa prevalensi asma lebih tinggi pada perempuan dari pada laki-laki dengan persentase mencapai 60\% (WHO, 2011).

\section{Jenis Kelamin}

Tabel II. Karakteristik pasien asma berdasarkan umur

\begin{tabular}{lll}
\hline Usia & Frekuensi & $\begin{array}{l}\text { Persentase } \\
(\%)\end{array}$ \\
\hline $60-74$ tahun & 29 & 82 \\
$75-90$ tahun & 6 & 17 \\
\hline Total & 35 & 100
\end{tabular}

Usia pada pasien asma geriatri pada penelitian ini dibagi mejadi 2 kategori yaitu, lanjut usia (60-74 tahun), lanjut usia tua (75-90 tahun) (Azizah, 2011). Berdasarkan pada Tabel II. dapat dilihat bahwa usia pasien lebih bayak diderita oleh pada usia lanjut usia 6074 tahun yaitu sebanyak 29 pasien (82\%) kemudian dibawahnya lagi pada pasien lanjut usia tua 75-90 tahun yaitu sebanyak 6 pasien (17\%).

\section{B. Pola Penggunaan Obat}

Berdasarkan data penelitian pada kelompok usia pasien asma pada geriatri di Instalasi Rawat Jalan RSUD Kraton Kabupaten Pekalongan periode Januari-Desember 2020 didapatkan data golongan obat tertera dalam table. 
Tabel III. Golongan Obat Yang di Gunakan

\begin{tabular}{ll}
\hline Golongan Obat & Nama Obat \\
\hline SABA & Ventolin \\
& Salutamol \\
& Lasal \\
& Fluxotid \\
& Pulmicort \\
Mukolitik & Ambroxol \\
Duiretik & Furosemid \\
Hipertensi & Amplodipin \\
& Spironolacton \\
& Adalat oros \\
Kortikosteroid & Candesartan \\
Ulkus & Metil prednisolone \\
Anti Diabetes & Dexamethason \\
Antihistamin & Ranitidin \\
Analgetik & Lansoprazol \\
& Acarbose \\
& Cetirizin \\
& Paracetamol \\
\hline
\end{tabular}

Pada penelitian ini golongan obat yang sering digunakan adalah SABA yaitu sebanyak 5 obat kemudian golongan obat hipertensi yaitu sebanyak 4 obat. Agonis beta 2 (SABA) merupakan terapi pilihan pada serangan asma dan sangat bermanfaat sebagai terapi pada asma. Mekanisme dari golongan obat ini adalah bekerja dengan menstimulasi reseptor beta 2 adrenergik yang mengakibatkan relaksasi otot polos pada jalan nafas (PDPI, 2010).

\section{Penyakit Penyerta}

Penyakit penyerta pada pasien geriatri diketahui dari diagnosis medis dokter.

Tabel IV. Karakteristik Pasien Berdasarkan Penyakit Penyerta Penyakit penyerta Jumlah

\begin{tabular}{ll}
\hline Dispepsia & 6 \\
Hipertensi & 4 \\
Diabetes & 1 \\
\hline Total & 11 \\
\hline
\end{tabular}


Dari data pasien diatas penyait penyerta yang paling banyak terjadi pada penelitian ini adalah dispepsia yaitu sebanyak 6 pasien dan juga hipertensi sebanyak 4 pasien. Hal tersebut disebabkan karena gejala yang dialami pada dispepsia berupa nyeri pada ulu hati dan bisa dapat memicu terjadinya sesak nafas. Sesak nafas yang terjadi karena terdapat gangguan pada lambung, termasuk dispepsia, sama sekali tidak boleh dianggap sepele, karena sesak nafas pada penyakit ini bisa mengakibatkan timbulnya komplikasi pernafasan yang mengancam jiwa.

\section{Bentuk Sediaan}

Bentuk Sediaan pada pasien geriatri diketahui dari obat yang diberikan dokter.

Tabel V. Karakteristik Obat Berdasarkan Bentuk Sediaan

\begin{tabular}{ll}
\hline $\begin{array}{l}\text { Bentuk } \\
\text { Sediaan }\end{array}$ & Jumlah \\
\hline Tablet & 69 \\
Inhalasi & 33 \\
Sirup & 15 \\
\hline Total & 116
\end{tabular}

Berdasarkan pada tabel V dapat dilihat bahwa bentuk sediaan yang paling banyak digunakan adalah bentuk sediaan tablet yaitu sebanyak 69 kemudian ada sediaan inhalasi sebanyak 33 lalu selanjutnya ada sediaan sirup sebanyak 15. Hal ini dikarenakan pasien dalam penelitian ini ialah lansia, dalam hal ini pasien sering menggunakan sediaan tablet karena penggunaan inhalasi hanya diberikan jika pasien dalam keadaan rawat inap saja dan hanya pada keadaan penting saja dan susah dalam menggunakan obat per oral. Pengobatan asma dapat diberikan melalui berbagai cara yaitu secara inhalasi, dan juga secara oral. Kelebihan pemberian obat melalui inhalasi dibandingkan dengan cara lain adalah lebih efektif untuk dapat mencapai konsentrasi tinggi di jalan napas, efek sistemik minimal, hanya beberapa obat saja yang bisa diberikan melalui inhalasi (PDPI, 2010)

\section{Evaluasi Penggunaan Obat}

Evaluasi penggunaan obat merupakan analisis dari penggunaan obat atau sebagai alat untuk melakukan jaminan mutu dengan tujuan mendapatkan penilaian penggunaan obat pada pasien yang disesuaikan dengan kriteria yang ditetapkan, tujuan dari evaluasi ini adalah untuk perbaikan dalam pemberian suatu obat agar bis meningkatkan keamanan, kualitas, dan efektivitas dari pengggunaan obat (Wiffen.,dkk 2014). Pasien Asma di Instalasi Rwat Jalan RSUD Kraton Kabupaten Pekalongan periode Januari - Desember 2019. Kasus yang akan di evaluasiyaitu tepat obat, tepat dosis, tepat indikasi, dan juga tepat cara pemberian sesuai dengan Pedoman Penggunaan Obat Rasional Kemenkes RI (2011). 


\section{Tepat Dosis}

Tepat dosis merupakan kesesuaian pemberian obat dengan rentang dosis terapi yang ditentukan, berdasarkan dari dosis penggunaan perhari dengan penyesuaian kondisi pasien baik umur ataupun yang lain. Bila peresepan obat dalam rentang dosis minimal dan juga dosis per hari maka peresepan dikatakan tepat dosis (Untari., dkk, 2018).

Tabel VI. Distribusi frekuensi tepat dosis obat asma pada pasien geriatri

\begin{tabular}{lll}
\hline Tepat Dosis & Frekuensi & Persentase (\%) \\
\hline Tepat & 30 & 85,7 \\
Tidak tepat & 5 & 14,3 \\
\hline Total & 35 & 100
\end{tabular}

Berdasarkan data hasil penelitian diatas didapatkan sebanyak 30 pasien $(85,7 \%)$ masuk dalam kategori tepat dosis dan sebanyak 5 pasien $(14,3 \%)$ tidak sesuai dengan literatur yang ada. Penggunaan obat yang belum sesuai dengan literatur yang ada, selain itu pemberian obat pada lansia seharusnya mendapatkan obat dengan perhitungan dosis yang sesuai dengan literatur dan juga usia, karena keadaan fisik dari pasien sudah mulai menurun sehingga pemberian dosis harus sesuai dengan literatur yang ada (Syamsuni, 2016). Penggunaan obat yang tidak tepat bisa berakibat fatal pada pasien dan juga bisa mengalami overdosis, mengalami risiko berkembangnya masalah kesehatan atau memperpanjang atau bisa juga memperburuk kesakitan yang diderita oleh pasien (Kemenkes RI,

2011).

\section{Tepat Indikasi}

Tepat indikasi merupakan kesesuian pemberian obat antara indikasi obat dengan diagnosa dari dokter. Pemilihan obat dilakukan dengan mengacu dari penegakkan diagnosa pada pasien, lalu dilakukan penilaian ketepatan indikasi pengobatan dilakukan berdasarkan pengobatan yang sesuai dengan penyakit yang dialami oleh pasien.

Tabel VII. Distribusi Frekuensi Tepat indikasi obat asma pada pasien geriatri

\begin{tabular}{lll}
\hline $\begin{array}{l}\text { Tepat } \\
\text { Indikasi }\end{array}$ & Frekuensi & $\begin{array}{l}\text { Persentase } \\
(\boldsymbol{\%})\end{array}$ \\
\hline Tepat & 35 & 100 \\
Tidak Tepat & 0 & 0 \\
\hline Total & 35 & 100
\end{tabular}

Berdasarkan data hasil dari penelitian diatas, semua pasien asma termasuk dalam kategori tepat indikasi. Obat yang dikaji berdasarkan golongan obat, dimana semua obat 
yang didapat oleh pasien sudah termasuk dalam obat yang diindikasikan untuk penyakit asma. Tepat indikasi yaitu obat yang digunakan sesuai dengan indikasi dan juga diagnosa pada pasien, artinya keputusan pemberian resep obat didasarkan pada indikasi yang ditemukan pada pasien dan juga terapi obat yang diberikan merupakan terapi obat yang aman dan juga efektif.

\section{Tepat Obat}

Ketepatan pemilihan obat dilihat dari kesesuain dari pemberian obat anti asma yang dapat dilihat dari ketepatan kelas lini terapi, jenis dan juga kombinasi obat bagi pasien (Untari.,dkk, 2018). Berikut hasil penelitiannya.

Tabel VIII. Distribusi Frekuensi Tepat
\begin{tabular}{lll}
\hline Tepat & Frekuensi & Persentase \\
Obat & & $(\%)$ \\
\hline Tepat & 35 & 100 \\
Tidak Tepat & 0 & 0 \\
\hline Total & 35 & 100
\end{tabular}

Berdasarkan hasil penelitian diatas di dapatkan hasil bahwa seluruh pasien asma pada geriatri dengan total 35 pasien termasuk dalam kategori tepat obat. Obat yang diperoleh pasien telah dikaji berdasarkan kelas lini terapi dan juga kombinasi obat pada pasien yang berpengaruh terhadap penyakit pasien. Pemilihan obat yang tidak tepat akan mengakibatkan tujuan terapi tidak tercapai sehingga pasien merasa dirugikan, sehingga perlu pemilihan obat berdasarkan kemanfaatan dan keamanan obat, keefektifan obat, kesesuaian obat, serta toksisitas maupun efek samping obat (Depkes RI, 2010)

\section{Tepat Cara Pemberian}

Ketepatan cara pemberian obat terhadap pasien dilihat dari kesesuaian antara rute obat dengan usia pasien dan referensi buku panduan. Pasien pediatri lebih aman jika menggunakan obat dalam bentuk sediaan oral, selain itu juga dapat meminimalisir dari biaya pengobatan pasien.

Tabel IX. Distribusi Frekuensi Tepat Cara Pemberian obat asma pada pasien geriatri

\begin{tabular}{lll}
\hline $\begin{array}{l}\text { Tepat Cara } \\
\text { Pemberian }\end{array}$ & Frekuensi & $\begin{array}{l}\text { Persentase } \\
(\boldsymbol{\%})\end{array}$ \\
\hline $\begin{array}{l}\text { Tepat } \\
\text { Tidak tepat }\end{array}$ & 0 & 100 \\
\hline Total & 35 & 0 \\
\hline
\end{tabular}

Berdasarkan data penelitian diatas, semua pasien termasuk dalam kategori tepat cara pemberian. Ketetapan cara pemberian obat terhadap pasien dilihat dari 
kesesuaian antara rute obat dengan usia pasien dan referensi buku panduan. Semua obat yang diberikan melalui rute per oral, baik dalam sediaan tablet, sirup, maupun inhaler. Pemberian obat secara per oral merupakan cara yang paling mudah, murah dan juga aman (Dermawan, 2015).

Hasil penelitian ini juga sesuai dengan peneliti lain yaitu Handayani (2014) menunjukkan tepat cara pemberian sebanyak $100 \%$. Cara pemberian obat kepada pasien sudah sesuai dengan rute pemberian obatnya misalnya saja obat nebulizer ventolin yaitu pemberian obatnya dengan cara dihirup hal ini bertujuan ketika pasien mengalami sesak nafas maka pasien dengan segera menggunakan nebulizer ventolin karena memiliki efek yang cepat karena obat langsung masuk ke dalam sistem pernafasan.

\section{Keterbatasan Penelitian}

Jumlah responden yang hanya berjumlah 35 orang, tentunya masih kurang untuk menggambarkan keadaan yang sesungguhnya, Subyek penelitian hanya difokuskan hanya pada pasien yang berusia 60 tahun keatas saja, sedangkan pada teori batasan usia geriatri mulai dari usia 45 tahun hingga 90 tahun keatas, Waktu pengambilan data yang diberikan tidak cukup lama karena selama kondisi pandemi covid-19 pengambilan data harus bergantian dengan peneliti lain, sehingga terbatas dalam pengambilan jumlah rekam medik untuk penelitian ini.

\section{KESIMPULAN}

Berdasarkan penelitian yang sudah dilakukan, maka kesimpulan dari penelitian ini adalah:

1. Ketepatan pemilihan tepat dosis pada terapi asma pada pasien geriatri di Instalasi Rawat Jalan RSUD Kraton Kabupaten Pekalongan pada tahun 2019 sebanyak 85,7\%.

2. Ketepatan pemilihan tepat indikasi pada terapi asma pada pasien geriatri di Instalasi Rawat Jalan RSUD Kraton Kabupaten Pekalongan pada tahun 2019 sebanyak 100\%.

3. Ketepatan pemilihan tepat obat pada terapi asma pada pasien geriatri di Instalasi Rawat Jalan RSUD Kraton Kabupaten Pekalongan pada tahun 2019 sebanyak 100\%

4. Ketepatan pemilihan tepat cara pemberian obat pada terapi asma pada pasien geriatri di Instalasi Rawat Jalan RSUD Kraton Kabupaten Pekalongan pada tahun 2019 sebanyak $100 \%$.

\section{SARAN}

\section{Bagi Peneliti Lain}

Diharapkan akan adanya penelitian selanjutnya dengan variabel yang berbeda dan dengan metode yang berbeda agar bisa memperbanyak lagi referensi tentang pengobatan asma pada pasien geriatri.

\section{Bagi Instansi}

diharapkan terapi pengobatan asma pada pasien geriatri di instalasi farmasi ditingkatkan lagi hasil pengobatannya agar hasilnya bisa memuaskan dan . 


\section{Bagi Institusi}

Diharapkan agar nantinya pihak instansi bisa memperbanyak referensi tentang asma khususnya asma pada pasien geriatri

\section{Ucapan Terima Kasih}

Penulis mengucapkan terima kasih kepada Dosen Pembimbing Skripsi yang telah membantu selama proses penelitian ini.

\section{DAFTAR PUSTAKA}

Dermawan, D. 2015. Farmakologi Untuk Keperawatan. Yogyakarta : Gosyen

Global Initiative for Asthma (GINA). 2016. Global Stategy for Asthma Management and Prevention.

Hussar, D.A., 2009 Patient Complience, in Remington : The Science and Practice of Pharmacy, volume II, USA : The philadelpia Collage of Pharmacy and Science.

Kemenkes RI. 2011. Modul Penggunaan Obat Rasional. Jakarta : Kementrian Kesehatan Republik Indonesia.

Okti, R.M.,dkk, 2016. Evaluasi Terapi pada Paien Asma di Rumah Sakit Khusus Paru Respirasi Yogyakarta Daerah UPKPM Kalasan Periode November 2014- Januari 2015. Jurnal Ilmiah Farmasi Vol.12 No.2.Universitas Islam Indonesia

Sarafino, E.P., Timothy W. Smith. Health Psychology: Biopsychosocial Interactions, 7th edition. Amerika Serikat: John Wiley dan Sons, Inc.

Untari, Eka K., Agilina., Alvani R ., Susanti., Ressi (2018). Evaluasi Rasionalitas Penggunaan Obat Antihipertensi di Puskesmas Siatan Hilir Kota Pontianak tahun 2015. Pharmaceutical Science adn Research 5

Wiffen, Philip., Mitchell M., Snelling., Melanie., dan Stoner., Nicola. (2014). Farmasi Klinik

OXFORD. Jakarta: EGC.World Health Organization (WHO). (2017). Asthma. 